\title{
Effects of hydroxyapatite nanoparticles on liver enzymes and blood components
}

\author{
Gamagedara TP* and Ziana HF \\ Faculty of Allied Health Sciences, University of Peradeniya, Augusta Hill, Peradeniya, Sri Lanka
}

\begin{abstract}
Hydroxyapatite nanoparticles (HANP) have different biomedical applications such as a bone grafting material due to its similarity with hydroxyapatite (HA) in natural bone. As nanoparticles (NP) HANP can be distributed everywhere in the body with blood circulation, and it can be mainly accumulated in the lung, liver and spleen. Therefore, biocompatibility of HANP should be confirmed through both in vivo and in vitro experiments before using it as a bone grafting material. There are lots of studies on biocompatibility of HANP based on in-vitro cell cultures. However, there are few biocompatibility studies of HANP based on in-vitro liver enzyme analysis and blood component analysis. This review tries to show the possible effects of HANPs on liver enzymes and blood components.
\end{abstract}

\section{Nanoparticles}

Nanotechnology is defined as the "design, characterization, production and application of structures, devices and systems by controlling shape and size at the nanoscale" $(<100 \mathrm{~nm})$. Therefore, any particle with even at least one diameter lies below $100 \mathrm{~nm}$ is considered to be a NP. Even though these NPs possess the same chemical structure as the larger particle, their chemical, physical, and electrical properties are different from larger particles [1]. Therefore, these NPs are attracted in many fields based on their unique properties such as small size (surface area and size distribution), chemical composition (purity, crystallinity, electronic properties, etc.), surface structure (surface reactivity, surface groups, inorganic or organic coatings, etc.), solubility, shape, and aggregation. NPs are either natural or synthesized [2,3]. NPs can be released into the environment in natural processes such as volcanic eruption. Apart from that, the level of NPs in the environment can be increased due to combustion by-products, carbon black and urban particulate matters released in the industrial pollution. NPs are synthesized as those are used in many areas such as industry (e.g., semiconductors, computers and engineering), environmental sciences (e.g., water purification, and pathogen detection and identification), food sciences (e.g., sterilization and prolonged shelf-life), biology (in vitro diagnostics) and medicine (drug delivery and imaging) [4].

\section{Hydroxyapatite nanoparticles}

HANP is defined as the HA material with the size of less than $100 \mathrm{~nm}$ [5]. HANP is also categorized under the group of calcium phosphate [6]. HA is present in igneous and metamorphic rocks as a natural mineral. Moreover, it is present in bones and teeth as the major inorganic component [7].

\section{Structure of the bone}

Bone is a unique material possessing, the structural hierarchy at different length scales. It consists of different hierarchical levels; "macrostructure level $(10 \mathrm{~mm}$ - several $\mathrm{cm}$, or the whole bone level), mesostructure level $(0.5-10 \mathrm{~mm})$, microstructure level $(10-500 \mu \mathrm{m})$ and nanostructure level (less than $1 \mu \mathrm{m}$ ). At the nanostructure level (size less than $1 \mu \mathrm{m}$ ), bone can be considered as a multi-phase nanocomposite consisting of an organic phase, an inorganic phase and water. The main element of the organic phase is type I collagen present in the staggered pattern. The inorganic phase consists of mainly nanosized HA crystals as plates. These mineral crystals are located within the gap-overlap region of collagen fibrils with a specific crystalline orientation. Furthermore, mineral crystals are located outside the collagen fibrils. Together with collagen and minerals constitute a mineralized fibril structure [8]. At the next hierarchical structure, the arrangement of mineralized collagen fibril in the lamella is described. These mineral filled collagen fibrils are arranged into arrays in which this arrangement the fibril axes and the crystal layers are all organized into a 3-dimensional structure that makes up a single layer in lamella of bone a few microns thick. In the thicker lamellae, the fibrils are parallel to the boundary, but the crystal layers are rotated out of the plane of the boundary to produce the remarkable macroscopic scale of bone from the molecular scale; the alternating lamellae are organized into larger ordered structures in many bones [9]. The mechanical properties of bone are particular in those at the micro and nanostructure level [10] (Figure 1) (Tables 1 and 2).

\section{Uses of HANP}

HANPs have excellent biological characteristics, such as nonimmunogenicity, noninflammatory behaviour, good biocompatibility and high osteoconductivity and osteoinductivity. Therefore these distinct features of HANP enable a wide range of potential applications of HANP as a gene carrier, and in bone tissue engineering, drug delivery, orthopaedic surgery, $[11,12]$ and cosmetics and dental care products [13].

${ }^{\star}$ Correspondence to: Gamagedara TP, Faculty of Allied Health Sciences, University of Peradeniya, Augusta Hill, Peradeniya, Sri Lanka, E-mail: tpiumnil@pdn.ac.lk

Received: September 27, 2018; Accepted: October 05, 2018; Published: October 08,2018 


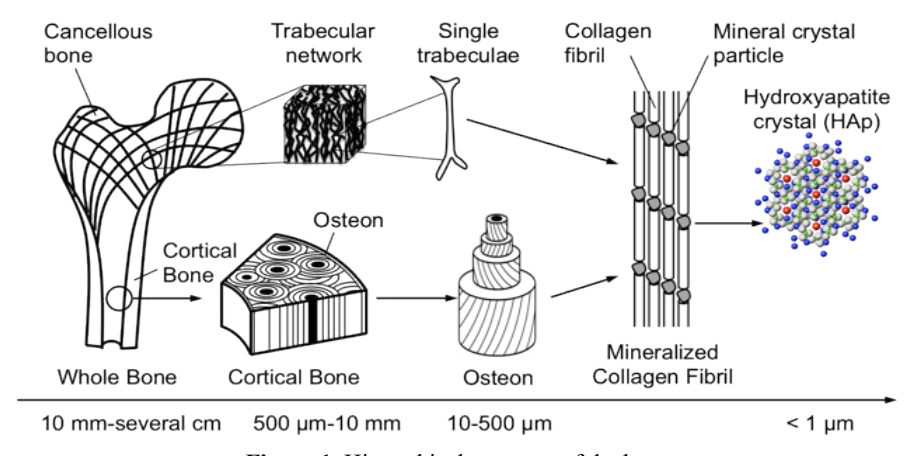

Figure 1. Hierarchical structure of the bone

Table 1. The composition of bone -Organic phase (Composition slightly be varied from species to species and bone to bone) (Gamagedara, 2016)

\begin{tabular}{|l|c|}
\hline Organic phase & $\mathbf{W t} \%$ \\
\hline Collagen & $\sim 20$ \\
Water & $\sim 09$ \\
$\begin{array}{l}\text { Non-collagenous proteins (osteocalcin, osteonectin, osteopontin, } \\
\text { thrombospondin, morphogenetic proteins, sialoprotein, serum proteins) }\end{array}$ & $\sim 03$ \\
$\begin{array}{l}\text { Polysaccharides, lipids, cytokines } \\
\text { Primary bone cells: osteoblasts, osteocytes, osteoclasts }\end{array}$ & Traces \\
\hline
\end{tabular}

Table 2. The composition of bone- Inorganic phase (Gamagedara, 2016)

\begin{tabular}{|l|c|}
\hline Inorganic phase & $\mathbf{W t} \%$ \\
\hline Hydroxyapatite (HA) & $\sim 60.0$ \\
Carbonate & $\sim 04.0$ \\
Citrate & $\sim 00.9$ \\
Sodium & $\sim 00.7$ \\
Magnesium & $\sim 00.5$ \\
$\mathrm{Cl}, \mathrm{F}^{-}, \mathrm{K}^{+}, \mathrm{Sr}^{2+}, \mathrm{Pb}^{2+}, \mathrm{Zn}^{2+}, \mathrm{Cu}^{2+}, \mathrm{Fe}^{2+}$ & Traces \\
\hline
\end{tabular}

\section{NP used for drug delivery}

Applications of NP in medicine include drug delivery, both in vitro and in vivo diagnostics, nutraceuticals and production of improved biocompatible materials. NPs are attracted in medicine based on some important and unique features such as their surface to mass ratio that is much larger than that of other particles, their quantum properties and their ability to adsorb and carry other compounds. NPs have a relatively large (functional) surface which is able to bind, adsorb and carry other compounds such as drugs, probes and proteins [14]. In medicine, nanotechnology is being used to deliver drugs and imaging agents, helping to improve solubility, change pharmacokinetic profiles and increase uptake to target sites, increase blood circulation half-life and reducing immunogenicity [4]. The aims for NP entrapment of drugs are either enhanced delivery to, or uptake by, target cells and/or a reduction in the toxicity of the free drug to non-target organs. Both situations will result in an increase of therapeutic index, the margin between the doses resulting in a therapeutic efficacy (e.g. tumour cell death) and toxicity to other organ systems. For these aims, the creation of long-lived and target-specific NPs is needed [14]. In the last two decades, a number of NP-based therapeutic and diagnostic agents have been developed for the treatment of cancer, diabetes, pain, asthma, allergy, infections, and so on. HANP is also used for drug delivery and tissue engineering. These usually make a composite containing HA and other ingredients, such as anti-infection drugs, bone growth factors, and biodegradable polymers [5].

\section{Bone grafting}

Bone grafting is a surgical procedure that replaces missing bone with material from patient's own body, artificial, synthetic or natural substitutes. According to the material used, bone grafting can be classified into several groups such as autograft which involves utilizing bone obtained from the same individual as a graft, allograft which involves utilizing bone obtained from another individual, xenograft which involves utilizing bone obtained from a different species, ceramic based bone graft involves ceramics either alone or combination with another material (e.g., calcium sulfate, bioactive glass and calcium phosphate), polymer based bone graft substitute performed with either naturally occurring polymers (e.g., Healos) or synthetic polymers (e.g., Cortoss) and alloplastic graft where HA or calcium carbonate is used [15] (Table 3).

The prime objective of bone grafting is the obtaining of grafted bone equivalent to the autogenous bone. This is achieved inducing the regeneration of the living tissue through the restoration of the defected bone. Therefore, the material used for the bone grafting providing a framework for regeneration of new bone. According to the way of regeneration (in vivo response), bone grafting materials are 3 types. Those are; "osteoconductive, osteoinductive and osteogenic. HA comes under the osteoconductive bone grafts which serve as a structural framework through which the host bone infiltrate and regenerate a new bone tissue [11] (Figure 2).

\section{HANP as a bone grafting material}

Structure of the HA used for the bone grafting is crystallographically similar with natural bone mineral. The HA derived from either natural sources or synthetic sources is recognized as bioactive substance since it forms a strong chemical bond with host bone tissue. Therefore, HA is considered as a good bone grafting material. Moreover, HA is not only bioactive but also osteoconductive, non-toxic and non-immunogenic [11]. The physiochemical, mechanical, and biological properties which make HA an appropriate bone grafting material are described in Table 3.

Recently, considering smaller size, higher surface area and roughness of HANP, HANP is more often used than micro scale materials as bone substitutes, tissue engineering scaffolds, coatings etc. Many studies report that HANP is used to form a three-dimensional biomimetic composite with chitosan, collagen-like polymers [16], and other bioactive molecules [17]. The composite materials can also be where the synthesized material mimics the natural bone's inorganic and organic phase composition [18]. The HANP composite scaffolds with appropriate porous structure, biodegradability and mechanical properties can induce osteoblast adhesion, proliferation, and differentiation, increasing their osteoinductivity and osseointegrative capacity $[19,20]$ (Table 4$)$.

\section{Negative effects of NPs}

In addition to the advantages of NPs, they can have toxicity effects on physiological systems of animals and human [21]. There are some studies revealing that the potential of nanoparticles to alter normal physiology by interacting with biomolecules in living cells thereby causing adverse effects at the cellular, subcellular, and protein levels [22].

Before the internal use of any biosynthesized material, it should be checked for biocompatibility. 'Biocompatibility' is usually considered to be the tolerance of liquid or solid body elements to the implant, 'blood compatibility (haemocompatibility)' is the tolerance of blood to the implant [23]. There are several in vitro and in vivo studies which have been performed to identify whether there is a toxic effect of HANP when it is used as a bone replacement or therapeutic material. These toxicological studies are needed to ensure how much HANP are biocompatible. When HANPs are used for bone replacement, 
Table 3. Bone grafting materials (Murugan and Ramakrishna, 2005).

\begin{tabular}{|c|c|c|c|c|}
\hline Biomaterials & Advantages & Applications & Applications & Examples \\
\hline Metal and alloy & $\begin{array}{l}\text { Too strong, tough, } \\
\text { Ductile }\end{array}$ & Dense, may corrode & $\begin{array}{l}\text { Bone plates, loadbearing } \\
\text { bone implants, } \\
\text { dental arch wire, and } \\
\text { dental brackets }\end{array}$ & $\begin{array}{l}\text { Titanium, stainless } \\
\text { steel, Co-Cr alloys, } \\
\text { and Ti alloys }\end{array}$ \\
\hline Ceramic & $\begin{array}{l}\text { Bioinert Bioactive Bioactive High } \\
\text { resistance to wear }\end{array}$ & $\begin{array}{l}\text { Brittle, poor tensile, } \\
\text { low toughness, lack } \\
\text { of resilience }\end{array}$ & $\begin{array}{l}\text { Hip joints and load bearing } \\
\text { bone implants } \\
\text { Bone filler, coatings on } \\
\text { bio-implants, orbital implant, } \\
\text { alveolar ridge augmentation, } \\
\text { maxillofacial reconstruction, } \\
\text { and bone tissue engineering }\end{array}$ & $\begin{array}{c}\text { Alumina, zirconia HA, bioglass } \\
\text { TCP }\end{array}$ \\
\hline Polymer & $\begin{array}{l}\text { Flexible, resilient, } \\
\text { surface modifiable, } \\
\text { selection of chemical } \\
\text { functional groups }\end{array}$ & $\begin{array}{l}\text { Not strong, toxic of a } \\
\text { few degraded products }\end{array}$ & $\begin{array}{l}\text { Bone tissue scaffolds, bone } \\
\text { screws, pins, bone plates, } \\
\text { bone and dental filler, and } \\
\text { bone drug delivery }\end{array}$ & $\begin{array}{l}\text { Collagen, gelatin, } \\
\text { chitosan, alginate, } \\
\text { PLA, PGA, PLGA, } \\
\text { PCL, PMMA, PE }\end{array}$ \\
\hline Composite & $\begin{array}{l}\text { Strong, design flexibility, } \\
\text { enhanced mechanical } \\
\text { reliability than monolithic }\end{array}$ & $\begin{array}{l}\text { Properties might be varied } \\
\text { with respect to fabrication } \\
\text { methodology }\end{array}$ & $\begin{array}{l}\text { Bone graft substitutes, middle } \\
\text { ear implants, bone tissue scaffolds, } \\
\text { guided bone regenerative } \\
\text { membranes, } \\
\text { and bone drug delivery }\end{array}$ & $\begin{array}{c}\text { HA/collagen, HA/ } \\
\text { gelatin, HA/chitosan, } \\
\text { HA/alginate, HA/ } \\
\text { PLGA, HA/PLLA, } \\
\text { HA/PE }\end{array}$ \\
\hline Nanocomposite & $\begin{array}{l}\text { Larger surface area, high } \\
\text { surface reactivity, relatively } \\
\text { strong interfacial-bonding, } \\
\text { design flexibility, enhanced } \\
\text { mechanical reliability than } \\
\text { monolithic and/or microcomposite }\end{array}$ & $\begin{array}{l}\text { No optimized technique for } \\
\text { material processing }\end{array}$ & $\begin{array}{l}\text { Major areas of orthopaedics, tissue } \\
\text { engineering, and drug delivery }\end{array}$ & $\begin{array}{l}\text { Nano-HA/collagen, } \\
\text { Nano-HA/gelatin, } \\
\text { Nano-HA/chitosan, } \\
\text { Nano-HA/PLLA }\end{array}$ \\
\hline
\end{tabular}
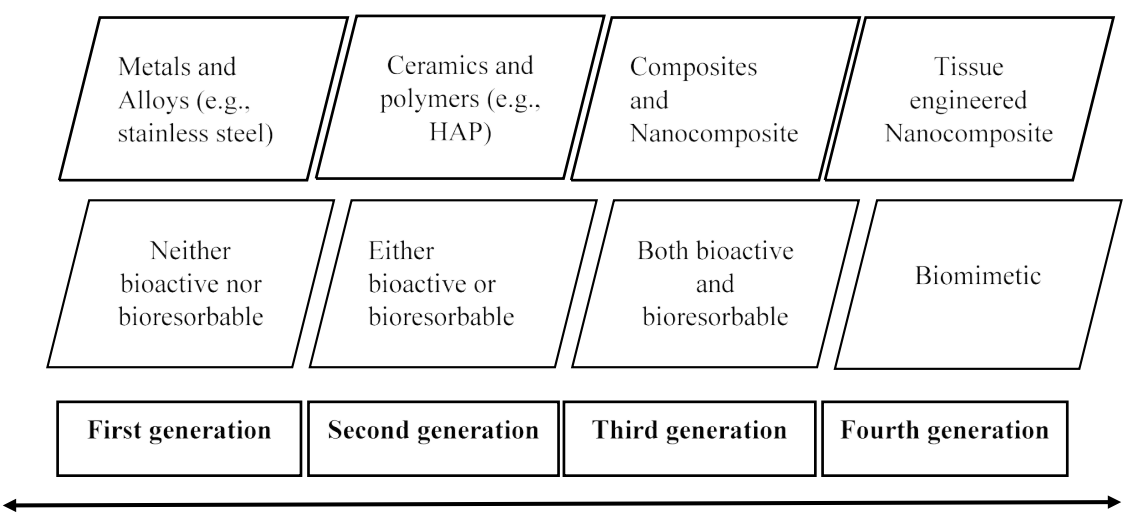

Figure 2. Evolution of bone grafting [11]

biocompatibility with blood components (haemocompatibility), enzymes and bone cells; "osteoblasts, osteocytes, osteoclasts" has to be ensured.

Entering of NPs into the vascular system intentionally and interacting with blood cannot be neglected. The NPs may have an effect on blood coagulation and haemolysis [24]. Different factors in blood such as platelet, blood vessels and coagulation factors affect the blood coagulation system. This factor favour the balance of pro and anti-coagulant process and maintain the hemostasis. A delicate balance between pro and anti-coagulant activities is required and any shift in this balance lead to the pathological process. NP may have an effect on blood coagulant system in a positive or negative ways depending on their desirability. Several physiochemical properties of NP result the interactions with component of blood coagulation system such as size (penetration ability, cellular up take, contact activation of coagulation depend on the size of NP), charge (membrane damage, protein interactions depend on charge), shape (cellular uptake, penetration of intracellular structure depend on the shape) and composition [4].

Several toxicological studies which were performed for HANP show that there is a cellular uptake in several cells such as liver, kidney etc. As an example, Sun et al. quantitatively analysed that intravenously administrated radiolabelled HANP was distributed everywhere in the body with blood circulation, but mainly accumulated in the lung, liver and spleen for over one month [25]. Some other toxicological studies, which is done for HANP, show that there is a main toxic effect on several excretory organs such as liver, spleen and kidney. To reflect the function of these excretory organs, some biochemical parameters such AST, ALT, ALP and blood urea nitrogen (BUN) can be used. Liu et al. found that the intravenous injection of rod-shaped NHA results in acute increases in ALT, AST, BUN and ALP in rabbits [26]. The intraperitoneally injected rod-shaped HANP results in no changes in AST, ALT and BUN in the serum of rats, but produces apoptosis in the liver cells and renal tubular epithelial cells. However they were able to detect that the HANP-Chitosan composite induced the significant elevation of BUN, Creatine (CR) and total bilirubin in the serum of rats as well as the apoptosis in the liver and kidney tissues with no inflammation and necrosis at eight weeks of exposure by intraperitoneal injection [20] (Figure 3).

The Figure 3 mainly describes that clearance of NP occurs through kidney, liver and macrophages. Solid arrows indicate the probable interactions. Dashed arrows indicate possible interactions. 
Table 4. Biological properties of HA (Murugan and Ramakrishna, 2005)

\begin{tabular}{|l|c|}
\hline Component or character & \\
\hline Chemical composition & $\mathrm{Ca}_{10}\left(\mathrm{PO}_{4}\right)_{6}(\mathrm{OH})_{2}$ \\
Ca/P molar & 1.67 \\
Crystal system & Hexagonal \\
Space group & $\mathrm{P} 63 / \mathrm{m}$ \\
Cell dimensions $\left(\mathrm{A}^{\circ}\right)$ & $\mathrm{a}=\mathrm{b}=9.42, \mathrm{c}=6.88$ \\
Young's modulus (GPa) & $80-110$ \\
Elastic modulus (GPa) & 114 \\
Compressive strength (MPa) & $400-900$ \\
Bending strength (MPa) & $115-200$ \\
Density (g/cm3) & 3.16 \\
Relative density (\%) & $95-99.5$ \\
Fracture toughness (MPa m1/2) & $0.7-1.2$ \\
Hardness (HV) & 600 \\
Decomposition temperature (_C) & $>1000$ \\
Melting point (C) & 1614 \\
Dielectric constant & $7.40-10.47$ \\
Thermal conductivity (W/cm K) & 0.013 \\
Biocompatibility & High \\
Bioactivity & High \\
Biodegradation & Low \\
Cellular-compatibility & High \\
Osteoinduction & Nil \\
Osteoconduction & High \\
\hline
\end{tabular}

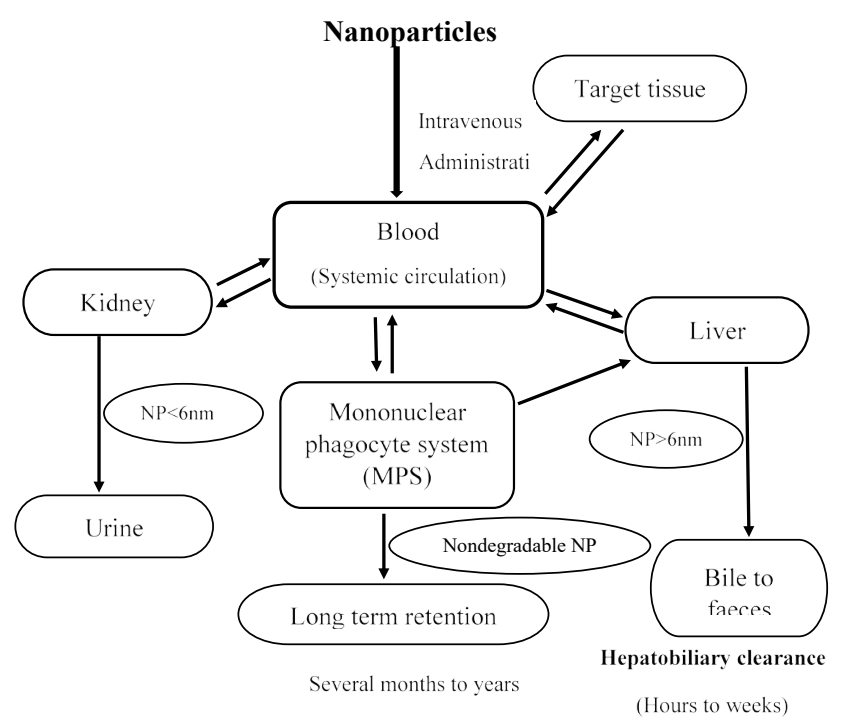

Figure 3. Schematic of nanoparticle clearance pathways (Zhang et al. 2016)

\section{Literature review}

The purpose of my research is to identify whether there is an effect of HANP on RBCs and liver enzymes. Several studies performed worldwide were used for supporting the hypothesis of this research.

There are studies which show that there is an interaction between NP with blood and proteins. As an example, study; "Interaction of colloidal gold nanoparticles with human blood: effects on particle size and analysis of plasma proteins binding profiles" performed in USA identified the 69 different proteins in plasma bound to the surface of gold nanoparticles, despite of the functional consequences of such binding are unknown. This study is one of proof that there may be an interaction between NP-blood and NP-enzyme as this study shows the interaction between proteins $[27,28]$.

There are some studies which have already shown that there is an effect of NPs on blood components. In vitro study which was carried out in Germany on haemocompatibility evaluation of different silver nanoparticle concentrations employing a modified Chandler-loop in vitro assay on human blood showed that there is a concentrationdependent hemocompatibility for silver NP and also higher concentration can affect various haematological parameters (positive effect on coagulation pathway, low platelet counts due to the platelet adhesion and haemolysis) [29]. The experiment which was done to identify the size-dependent effects of NP on enzymes in the blood coagulation cascade reveals that NP can cause charge dependent effect on coagulation pathway by activating, stabilizing, and inhibiting of an enzyme related to coagulation pathway [30]. The research conducted on the action on platelet activation and plasmatic coagulation carried out in Austria was able to disclose activation of the intrinsic pathway of plasmatic coagulation are the common mechanisms for increased clotting induced by NPs [31].

Furthermore, apart from studies done to identify the effect of NP on blood, there are studies which have performed to identify the effect of HANP on blood. Some in vivo studies show changes in blood cell counts and blood coagulation tests when blood component encounters HANP; as an example the result of research on NP sols of HA and titanium dioxide for haemocompatibility performed in vivo (rats) and in vitro (rabbit blood) shows that HANP obviously prolonged the time of bleeding, clotting and prothrombin in rats after intravenous injection and in vitro HANP did not cause haemolysis but did induce the aggregation of rabbit red blood cells (RBC) [24]. Another study which was conducted in China, Nano size and surface charge effects of HANP on RBC suspensions resulted in aggregation of RBC when positively charged HANP was used. It was concluded that positively charged HANP is electrostatically interacted to negatively charged RBC membrane and also this causes caves on the membrane but not the haemolysis [32].

Even though there is a comparatively higher number of research available for demonstrating the effect of NP on the liver, a limited number of experiments are performed to identify the effect of NP on enzyme activity.

Some research findings support the fact that NP enter and increase the liver enzyme levels in serum. There are several examples. The experiment, "Evaluation of iron oxide nanoparticles effects on tissue and enzymes of liver in rats" demonstrates that high concentration of iron oxide nanoparticles could be caused undesirable effects on liver with damage to hepatocyte and level elevation of liver enzymes such as AST, ALT and ALP [33]. The research, "Biochemical Evaluation of Silver Nanoparticles in Wistar Rats" indicates the alteration of rat tissue biochemical indices. According to this study silver NP mainly accumulates in the liver. Furthermore the effect of the oral administration of Ag NPs to rats on ALP, AST, and ALT did not follow a definite pattern but may suggest partial inactivation of enzyme activity or depression of enzyme synthesis [34].

There are some studies which show that NP can affect the activity of liver enzymes. As an example, the research, the toxicity effect of cerium oxide nanoparticles on ALT, AST and ALP enzymes in the male rat which was performed in Iran showed that there is an increased activity of ALT, AST and ALP when exposing to cerium oxide [35]. As an in vitro study the experiment on Zinc Oxide NP augments ALT, AST, ALP and lactate dehydrogenase (LDH) expressions in C2C12 cells carried out in Korea showed that activity of all tested enzyme was increased [36].

Even though there are no studies found to demonstrate the effect of HANP on the activity of liver enzymes, there are some studies on 
HANP which provides evidence for changing the activity of some other enzymes. As an example, the study was done in Russia about the 'effect of HANP on the kinetics of enzymatic gelation in milk' revealed HA strongly affects the processes of the enzymatic gelation in milk [37]. Another study performed by Dutta et al. [38], 'Nanotechnologyenabled enhancement of enzyme activity and thermo-stability: a study on impaired pectate lyase from attenuated Macrophomina phaseolina in Presence of HANP' discloses the dual role of HANP in enhancing activity and conferring thermostability.

Biological assessment requires candidate materials to be noncytotoxic and to be bio functional, able to elicit a beneficial hostresponse in a specific application [39]. There are several in vitro and in vivo studies which have been performed to identify whether there is a toxic effect of HA NPs when it is used as a bone replacement or therapeutic material. When HA NPs are used for bone replacement, biocompatibility with blood components (haemocompatibility), enzymes and bone cells have to be ensured.

\section{References}

1. Foo YY, Periasamy V, Kiew LV, Kumar GG, Malek SNA (2017) Curcuma manggaMediated Synthesis of Gold Nanoparticles: Characterization, Stability, Cytotoxicity, and Blood Compatibility. Nanomaterials 7: pii: E123. [Crossref]

2. Nel A, Xia T, Mädler L, Li N (2006) Toxic potential of materials at the nanolevel. Science 311: 622-627. [Crossref]

3. Gamagedara TP, Rathnayake UM, Rajapakse RMG (2018) "Facile synthesis of hydroxyapatite nanoparticles by a polymer-assisted method?: morphology, mechanical properties and formation mechanism," J Clin Invest 1: 1-5.

4. Ilinskaya AN, Dobrovolskaia MA (2013) Nanoparticles and the blood coagulation system. Part II: safety concerns. Nanomedicine 8:969-981. [Crossref]

5. Zhang L, Gu FX, Chan JM, Wang AZ, Langer RS, et al. (2008) Nanoparticles in Medicine? Therapeutic Applications and Developments. 83: 761-769.

6. Sari P, Yusuf M, Dahlan K, Witarto AB, (2009) "APPLICATION OF HYDROXYAPATITE IN PROTEIN PURIFICATION," 13: 134-140.

7. Alves NM, Leonor IB, Azevedo HS, Reis RL, Mano JF (2010) Designing biomaterials based on biomineralization of bone. J Mater Chem 20: 2911.

8. Tadano S, Giri B (2012) X-ray diffraction as a promising tool to characterize bone nanocomposites. Sci Technol Adv Mater 12: 064708. [Crossref]

9. Weiner S, Traub W, "Apatite," in Hawley's Condensed Chemical Dictionary, vol. 6, Hoboken, NJ, USA: John Wiley \& Sons, Inc., 2007, pp. 879-885.

10. Rho JY, Kuhn-Spearing L, Zioupos P (1998) Mechanical properties and the hierarchical structure of bone. Med Eng Phys 20: 92-102. [Crossref]

11. Murugan R, Ramakrishna S (2005) Development of nanocomposites for bone grafting. Compos SciTechnol. 65: 2385-2406.

12. Wang S, Wen S, Shen M, Guo R, Cao X, et al. (2011) Aminopropyltriethoxysilanemediated surface functionalization of hydroxyapatite nanoparticles: synthesis, characterization, and in vitro toxicity assay. Int J Nanomedicine 6: 3449-3459. [Crossref]

13. Tschoppe P, Zandim DL, Martus P, Kielbassa AM (2011) Enamel and dentine remineralization by nano-hydroxyapatite toothpastes. J Dent 39: 430-437. [Crossref]

14. De Jong WH, Borm PJ (2008) Drug delivery and nanoparticles:applications and hazards. Int J Nanomedicine 3: 133-149. [Crossref]

15. Kumar P, Vinitha B, Fathima G (2013) Bone grafts in dentistry. J Pharm Bioallied Sci 5: S125-127. [Crossref]

16. Wang J, Wang L, Fan Y (2016) Adverse Biological Effect of TiOâ, , and Hydroxyapatite Nanoparticles Used in Bone Repair and Replacement. Int J Mol Sci 17. [Crossref]

17. Kane R, Ma1 PX (2013) Mimicking the nanostructure of bone matrix to regenerate bone. Mater Today (Kidlington) 16: 418-423. [Crossref]

18. Gupta D, Venugopal J, Mitra S, Giri Dev VR, Ramakrishna S (2009) Nanostructured biocomposite substrates by electrospinning and electrospraying for the mineralization of osteoblasts. Biomaterials 30: 2085-2094. [Crossref]
19. Guo B, Lei B, Li P, Ma PX (2015) Functionalized scaffolds to enhance tissue regeneration. Regenerative Biomaterials.

20. Wang J, Wang L, Fan Y (2016) Adverse Biological Effect of TiOâ,, and Hydroxyapatite Nanoparticles Used in Bone Repair and Replacement. Int J Mol Sci 17. [Crossref]

21. Moore MN (2006) Do nanoparticles present ecotoxicological risks for the health of the aquatic environment? Environ Int.

22. Tiwari DK, Jin T, Behari J (2011) Dose-dependent in-vivo toxicity assessment of silver nanoparticle in Wistar rats. Toxicol Mech Methods 21: 13-24. [Crossref]

23. Tsai WB, Grunkemeier JM, Horbett TA (1999) Human plasma fibrinogen adsorption and platelet adhesion to polystyrene. J Biomed Mater Res 44: 130-139. [Crossref]

24. Chen Z, Meng H, Xing G, Chen C, Zhao Y, et al. (2006) Acute toxicological effects of copper nanoparticles in vivo. Toxicol Lett 163: 109-120. [Crossref]

25. Sun J, Xie G. Tissue distribution of intravenously administrated hydroxyapatite nanoparticles labeled with125I, in INEC 2010 - 2010 3rd International Nanoelectronics Conference, Proceedings, 2010.

26. Liu LP, Xiao YB, Xiao ZW, Wang ZB, Li C, et al. (2005) [Toxicity of hydroxyapatite nanoparticles on rabbits]. Wei Sheng Yan Jiu 34: 474-476. [Crossref]

27. Zhang YN, Poon W, Tavares AJ, McGilvray ID, Chan WCW (2016) Nanoparticle-liver interactions: Cellular uptake and hepatobiliary elimination. J Control Release 240: 332 348. [Crossref]

28. Dobrovolskaia MA, Patri AK, Zheng J, Clogston JD, Ayub N, et al. (2009) Interaction of colloidal gold nanoparticles with human blood: effects on particle size and analysis of plasma protein binding profiles. Nanomedicine. 5:106-117. [Crossref]

29. Krajewski S1, Prucek R, Panacek A, Avci-Adali M, Nolte A, et al. (2013) Hemocompatibility evaluation of different silver nanoparticle concentrations employing a modified Chandler-loop in vitro assay on human blood. Acta Biomater 9: 7460-7468. [Crossref]

30. Sanfins E, Augustsson C, Dahlbäck B, Linse S, Cedervall T (2014) Size-dependen effects of nanoparticles on enzymes in the blood coagulation cascade. Nano Lett 14: 4736-4744. [Crossref]

31. Fröhlich E (2016) Action of Nanoparticles on Platelet Activation and Plasmatic Coagulation. Curr Med Chem 23: 408-430. [Crossref]

32. Han Y, Wang X, Dai H, Li S (2012) Nanosize and surface charge effects of hydroxyapatite nanoparticles on red blood cell suspensions. ACS Appl Mater Interfaces, 4: 4616-4622. [Crossref]

33. Parivar K, Malekvand Fard F, Bayat M, Alavian SM, Motavaf M (2016). Evaluation of Iron Oxide Nanoparticles Toxicity on Liver Cells of BALB/c Rats. Iran Red Crescent Med J 18: e28939. [Crossref]

34. Adeyemi OS, Adewumi I (2014) Biochemical Evaluation of Silver Nanoparticles in Wistar Rats. Int Sch Res Notices 2014: 196091. [Crossref]

35. El Shaer SS, Salaheldin TA, Saied NM, Abdelazim SM (2017) In vivo ameliorative effect of cerium oxide nanoparticles in isoproterenol-induced cardiac toxicity. Exp Toxicol Pathol 69:435-441 [Crossref]

36. Pandurangan M, Kim DH (2015) ZnO nanoparticles augment ALT, AST, ALP and LDH expressions in C2C12 cells. Saudi J Biol Sci 22: 679-684. [Crossref]

37. Smykov IT, Severin AV, Bozhevolnov VE (2013) Effect of Hydroxyapatite Nanoparticles on Kinetics of Enzymatic Gelation in Milk, in PROCEEDINGS OF THE INTERNATIONAL CONFERENCE NANOMATERIALS: APPLICATIONS AND PROPERTIES, 2: 4-5.

38. Dutta N, Mukhopadhyay A, Dasgupta AK, Chakrabarti K (2013) Nanotechnology Enabled Enhancement of Enzyme Activity and Thermostability: Study on Impaired Pectate Lyase from Attenuated Macrophomina phaseolina in Presence of Hydroxyapatite Nanoparticle. PLoS One, 8:e63567. [Crossref]

39. Herath HMTU, Di Silvio L, Evans JRG (2005) Porous hydroxyapatite ceramics for tissue engineering. J Appl Biomater Biomech 3: 192-198.

Copyright: (C2018 Gamagedara TP. This is an open-access article distributed under the terms of the Creative Commons Attribution License, which permits unrestricted use, distribution, and reproduction in any medium, provided the original author and source are credited. 